\title{
La realidad y sus representaciones: una aproximación a la poética realista en la obra narrativa de Marta Sanz
}

Simó, Marta

University of Reading, Reino Unido

M.Simo-Comas@reading.ac.uk

Cita sugerida: Simó, M.(2018).La realidad y sus representaciones: una aproximación a la poética realista en la obra narrativa de Marta Sanz. En C. Somolinos Molina (ed.), "Escrituras del cuerpo: Marta Sanz". Olivar, 18 (27), e021. https://doi.org/10.24215/18524478e021 
La realidad y sus representaciones: una aproximación a la poética realista en la obra narrativa de Marta Sanz

Reality and its Representations: an Approach to the Realistic Poetics of Marta Sanz Narrative

Marta Simó

University of Reading, Reino Unido

M.Simo-Comas@reading.ac.uk

\section{Resumen:}

La obra de Marta Sanz, de marcada intencionalidad crítica y disidente, se inscribe en un contexto general que recupera para la literatura la política y la reflexión social. Sus novelas, que arrancan de la realidad más inmediata y tangible, dejan al descubierto las trampas de la imperante ideología neoliberal y cuestionan el modo en que ésta condiciona la conciencia colectiva y la experiencia individual. Partiendo de la concepción que Marta Sanz tiene de la escritura, ya sea en cuanto a su función social como en lo que respecta a su sentido estético, este artículo tiene como objetivo explorar aquellos aspectos que permiten enmarcar su obra dentro de una poética realista. Para ello se indagará primero en la naturaleza de esa realidad representada a través de sus temas y sus conflictos, una cuestión que se desarrollará en la primera sección de este artículo, "La novela es política”. En el segundo apartado, "La forma es ideológica”, se analizará el uso del lenguaje narrativo y su capacidad para construir sentido dentro de los parámetros de la estética realista. De este modo será posible establecer una continuidad entre sus novelas a pesar de las evidentes diferencias formales que existen entre las mismas.

Palabras clave: Realismo, Marta Sanz, Novela, Política, Estética.

\section{ABstraCt:}

The work of Marta Sanz is unmistakably critical and dissident in intent, inscribing itself into a wider contemporary movement to restore literature's role as political statement and social commentary. Rooted in immediate and tangible reality, her novels expose the flaws in the prevailing neo-liberal ideology and question the way in which this conditions collective consciousness and individual experience alike. Taking as its point of departure Marta Sanz's conception of literature, both as regards its social function and in terms of its aesthetic sense, this article aims to explore those aspects of her work that situate it within a poetics of realism. To this end, the first section of this article, "The Novel is Political", will examine the themes and conflicts that reveal the nature of the reality represented in her work. The second section, "The Form is Ideological", will analyse the narrative use of language and its capacity for constructing meaning within the parameters of the realist aesthetic. These approaches together make it possible to establish a line of continuity between her novels, despite the evident formal differences between them.

KEYWORDs: Realism, Marta Sanz, Novels, Politics, Aesthetics.

\section{INTRODUCCIÓN}

En la evolución estética e histórica del realismo, desde sus primeros paradigmas hasta sus últimas realizaciones, subyace una constante que define el verdadero carácter de este modo de representación. Más allá de los aspectos formales y miméticos de la obra, o del principio fundamental de la verosimilitud, prevalece en las ficciones realistas la voluntad continuada de cuestionar el mundo circundante para elaborar una lectura crítica del mismo. Es decir, además de observar e interpretar la realidad, el escritor realista se posiciona ideológicamente frente a la misma.

Esta dimensión ética, que establece una línea de continuidad entre las narrativas del XVI y la novela decimonónica que se fraguó al calor de la revolución burguesa, por citar dos de los momentos más emblemáticos de la poética realista, sigue viva hoy en el ámbito de la literatura hispánica peninsular. Los acontecimientos que conmocionaron el mundo, coincidiendo con la entrada del nuevo milenio, fueron el detonante para revitalizar cierta intención crítica en el seno de una tradición narrativa que, en las últimas 
décadas del XX, se había desarrollado casi de espaldas a las circunstancias históricas contemporáneas. A grandes rasgos, puede decirse que son tres las grandes líneas temáticas que actualmente canalizan esta forma de expresión literaria en la cual la indagación estética es inseparable de un diálogo moral con la sociedad.

La atmósfera de terror generada tras el 11-S introdujo en la novela un tono apocalíptico y nihilista que en España se vio intensificado a raíz de los brutales sucesos del 11-M. El correlato literario de este malestar metafísico se refleja en las obras de autores como Manuel Vilas, Ricardo Menéndez Salmón, Isaac Rosa o Juan Francisco Ferré, configuradas como escenarios distópicos en los que es posible leer el miedo a lo irracional y a la desestabilización, así como la desazón ante el deterioro inexorable del orden establecido.

Al fantasma del terrorismo transnacional y la amenaza del otro, instalado sólidamente en la conciencia colectiva, se añade el profundo desencanto que surgió al hilo de la gran recesión y que puso fin al espejismo de prosperidad creado desde el poder político y financiero. El relato de la crisis, que se ha ido afianzando como uno de los grandes temas literarios de la narrativa peninsular a lo largo de la segunda década del siglo XXI, es materia de un número creciente de novelas, hasta el punto de que la crítica y la industria editorial han acuñado ya el oportuno marbete de "novelas de la crisis" para categorizarlo. Esta nueva forma de realismo nos sigue hablando de la normalidad y de lo cotidiano, pero no desde el ensimismamiento, sino desde una perspectiva crítica y de condena con la que se exponen las desigualdades y las injusticias de una sociedad en que la desconfianza y el desconcierto son cada vez más profundos. A los nombres anteriormente citados podemos añadir los de Rafael Chirbes, Alberto Olmos, Pablo Gutiérrez, Elvira Navarro o Recaredo Veredas, entre otros; todos ellos autores diversos en cuanto a sus propuestas, pero con una misma voluntad de compromiso y denuncia ante la progresiva decadencia política, económica y moral que atenaza la sociedad del momento.

Por otra parte, la todavía bien arraigada temática de la recuperación de la memoria de la Guerra Civil, coexiste con un nuevo interés en un pasado más reciente, particularmente entre los autores nacidos en las décadas de los sesenta y setenta. Es ésta una línea narrativa que sitúa sus tramas en los años de la Transición y que debe enmarcarse dentro del debate que, en los últimos años y desde distintos ángulos de la política y la cultura, cuestiona la validez de un proceso dirigido por la oligarquía del franquismo. El punto de inicio de esta serie de novelas podría situarse en Lo real, de Belén Gopegui, de 2001, y El día del Watusi, de Francisco Casavella, aparecida por primera vez en tres volúmenes entre 2002 y 2003. Javier Cercas, Rafael Reig, Benjamín Prado o Javier Calvo, entre otros, son algunos de los autores que se inscriben también en esta tendencia, y si algo comparten, a pesar de sus distintos planteamientos, es la voluntad de cuestionar el discurso oficial y reescribir el pasado. Las estructuras políticas y económicas de hoy, con todas sus limitaciones y sus conflictos internos, sólo pueden entenderse a luz de las circunstancias que las construyeron, por lo que aun cuando estamos ante una forma de literatura de la memoria, la representación del pasado es también una reflexión sobre la persistencia de sus modos de organización en la actualidad.

En este contexto general, de carácter crítico y disidente, en el que se recupera para la literatura la política y la reflexión social, se enmarca la obra narrativa de Marta Sanz. Sus novelas arrancan de la realidad más inmediata y tangible, del compromiso necesario "con las cosas que pasan en la calle, en los trabajos o en los comedores familiares" (González et al., 2014, p. 24). El procedimiento fundamental para novelar la sociedad, tomando prestada la máxima galdosiana, debe ser un cuidadoso ejercicio de observación desde el cual sea posible ofrecer "un retrato del mundo en el que vivimos", y para ello hay que encontrar el ángulo de visión que saque a la luz las "falacias de la doble moral" (Sainz Borgo, 2011: 60). La literatura se convierte así en un arma para luchar contra las trampas que tiende la ideología dominante, la del neoliberalismo, que cristaliza en la cultura y que se ha apoderado de los medios de comunicación (Sanz, 2014a, p. 28-29).

Ésta es la realidad que Marta Sanz quiere revelar en su obra, la de "las perversidades del sistema en que vivimos" (Sainz Borgo, 2011, p. 60). Es la realidad de la crisis, la de la democracia defectuosa e insuficiente, la de los estereotipos caducos que siguen perpetuándose en el tiempo, la de la dictadura capitalista, la de una cultura que ha ido adaptando sus contenidos a las necesidades de una sociedad de consumo para convertirse en un ejercicio vacío. 
Sin embargo, junto con esta vertiente crítica del paradigma, que se ha venido a llamar "nuevo realismo", es posible encontrar también su opuesto: una variante neutra, alejada de cualquier posicionamiento ideológico, que elabora su discurso a partir de una descripción superficial y conformista del entorno y de la historia. Este remanente del costumbrismo, en el que la realidad se filtra sólo de manera superficial, responde, en palabras de Juan Francisco Ferré, "a una demanda comercial de una realidad asequible y estandarizada" (2011, p. 10). La situación resultante es que los dictados del consumo no sólo favorecen la existencia de una literatura desleída y comercial, sino que además dan lugar a la gran paradoja de vivir en un momento de supuesta libertad en el que sin embargo siguen existiendo barreras y obstáculos para la expresión libre.

En el opúsculo que Marta Sanz publicó en 2013 junto con otros autores en torno a la peligrosa mercantilización y adulteración ideológica de la literatura (Qué hacemos para construir un discurso disidente y transformador con aquello que hoy sirve para enmascarar la realidad y transmitir ideología: la literatura) no faltan reflexiones sobre las estrategias de censura y autocensura que impone el mercado. Al reducir la literatura a pura mercancía "los escritores renuncian a la lucidez, el sentido crítico, la intrepidez o el riesgo, para ejercer la autocensura, porque intuyen lo que deben o no deben escribir para ser acogidos en el seno del mercado" (2013, p. 32). La propia autora ha sufrido en sus carnes los efectos de la censura económica y comercial impuesta por el mercado en su novela Amour fou que, escrita en 2003 y rechazada por dos editoriales distintas de la península ibérica, sólo pudo ver la luz diez años después de su escritura en un sello independiente de Miami (Riaño, 2014).

El realismo literario de Marta Sanz se fundamenta en una lucha contra la idealización de la realidad, así como en la defensa de la dignidad ontológica de la novela, entendida como objeto cultural y como instrumento de denuncia social. La autora sigue creyendo en el poder transformador de la cultura, y por ello asume la escritura como un ejercicio de responsabilidad cuyo sentido último, más allá de la pulsión personal que la lleva a escribir, es impactar en la conciencia del lector y en el conjunto de la sociedad. Se trata, en suma, de una "literatura política" (González et al., 2014, p. 24).

Como la misma autora sostiene, esgrimiendo una de las premisas esenciales e intemporales del realismo, "la forma y el fondo de los textos literarios, como la ética y la estética, son conceptos indisolubles", por lo que "hay que aspirar a inquietar al receptor con propuestas que, por ser formalmente intrépidas, sean al mismo tiempo conceptualmente críticas" (Jiménez, 2013, s/p). Así, y partiendo de la compresión que Marta Sanz tiene de la escritura, ya sea en cuanto a su función social como en lo que respecta a su sentido estético, este artículo tiene como objetivo explorar aquellos aspectos que permiten enmarcar su obra dentro de una poética realista. Para ello es fundamental establecer primero cuál es la naturaleza de esa realidad representada a través de sus temas y sus conflictos, una cuestión que se desarrollará en la primera sección de este artículo, "La novela es política". En el segundo apartado, "La forma es ideológica", se indagará en el uso del lenguaje narrativo y en su capacidad para construir sentido dentro de los parámetros de la estética realista. Sólo así, desde la reflexión sobre los modos de representación de la realidad en la narrativa de Marta Sanz, será posible llegar a un entendimiento más preciso de su poética y establecer una continuidad entre sus novelas a pesar de las evidentes diferencias formales que existen entre las mismas.

\section{LA NOVELA ES POLÍTICA}

En una entrevista aparecida al hilo de la publicación de Daniela Astor y la caja negra, Marta Sanz subrayaba la dificultad de "hacer un ejercicio de abstracción de las coordenadas ideológicas del tiempo que a uno le toca vivir" (Ros, 2014, p. 261). Con esta idea, que supone en sí una declaración de principios, la autora retoma uno de los pilares conceptuales de la poética realista que ya fue enunciado por Galdós en 1897 en su discurso de ingreso en la Real Academia, titulado "La sociedad presente como materia novelable", y que podemos resumir en el argumento de que las condiciones del medio social en que vivimos constituyen un principio generador de la obra literaria (Pérez Galdós, [1897] 1991, p. 160). 
Salvando las distancias sociopolíticas que separan la España de la Restauración del actual momento histórico, resulta significativo el hecho de que entre ambas épocas parece configurarse una simetría de opuestos, pues si la novela decimonónica plasma la ideología de una clase burguesa emergente, el realismo de hoy, al hablarnos del nuevo orden social y la economía globalizada, o del discurso hegemónico del neoliberalismo, sólo puede constatar la decadencia y desaparición progresiva de esa clase media. El marco referencial es, en cualquier caso, el mismo -la historia en curso, con sus contradicciones, luchas y conflictosy la doble ambición del autor realista sigue siendo la de capturar en sus ficciones todos esos procesos e intervenir en el espacio público. Como sostiene Yvan Lissorgues, uno de los grandes teóricos del realismo decimonónico: "El realismo, cualquier realismo, está siempre relacionado con un momento histórico en que el hombre tiene conciencia de que hace o puede hacer o debe hacer la historia, o por lo menos que puede influir en ella" (2001, p. 55).

La obra de Marta Sanz se asienta, pues, en parámetros de carácter histórico, ideológico y ético, siempre centrales en la concepción e interpretación del ideario estético del realismo. En su ensayo No tan incendiario, al reflexionar sobre el concepto de realidad y los géneros más adecuados para darle forma literaria, califica la novela realista de "género decimonónico" y la presenta como un modo de expresión que todavía hoy puede servir "para dar cuenta, para visibilizar y para intervenir en un mundo también decimonónico donde siguen funcionando conceptos como el de lucha de clases” (2014a, p. 93).

Para la autora la escritura es, por lo tanto, un acto de responsabilidad respecto al mundo. Es posible modificar la visión de nuestro momento histórico sacando a la luz aspectos de la realidad que con frecuencia permanecen ocultos o simplemente ignorados, como "la ideología invisible que siempre se identifica con el poder", afirma Sanz en una entrevista reciente (Eusebio, 2014, p. 121). Sin embargo, aunque la capacidad transformadora de la literatura es siempre limitada, pues resulta imposible cambiar las estructuras del mundo desde la ficción, el ángulo estético del realismo favorece por lo menos la capacidad de impactar en las mentalidades:

Me gustaría creer que, cuando eso sucede y los textos sirven para visibilizar las realidades estropeadas, éstas se transforman. Pero no soy tan ingenua. Sin embargo, creo que los libros importantes sí pueden transformar poco a poco la conciencia colectiva, la subjetividad de una comunidad (Eusebio, 2014, p. 121).

Multiplicidad y multiperspectivismo son dos de los rasgos que mejor definen la realidad presente para Marta Sanz (2014a, p. 88). En el ámbito de lo ficcional, esta comprensión del mundo invoca de inmediato la existencia de un sujeto que humaniza el relato y lo acerca a la experiencia del lector, ya que el interés de la autora se dirige ante todo hacia "la literatura que habla de las cosas comunes, mayoritarias, pero enfocándolas desde una perspectiva en que esta normalidad suene, tenga razones y causas” (Sainz Borgo, 2011, p. 60). Se desliza así en el texto una conciencia que traslada los grandes argumentos ideológicos a la cotidianeidad y por la que se superponen las dos grandes coordenadas de cualquier relato realista: la colectiva y la individual.

De esta convergencia de lo colectivo y lo individual deriva otra línea de continuidad entre el realismo del XIX y el de los últimos años. La novela del gran periodo realista articula el desengaño del individuo frente a la historia y las circunstancias de su presente, así como la lucha del héroe por encontrar valores auténticos en una sociedad degradada. La impotencia es, inevitablemente, el sentimiento que prevalece en esta búsqueda. Como sostiene Joan Oleza, "es la fuerza portadora de la realidad la que acaba por imponerse al individuo, que fracasa" (1984, p. 7). Esta estructura ideológica es también consustancial a las ficciones realistas de hoy, por las que del mismo modo transitan personajes desencantados e incapaces de hacer frente a la lógica de las circunstancias, asfixiante y opresiva. Todo ello cristaliza en una serie de temas recurrentes: crisis económica, desigualdades sociales y de género, precariedad laboral, estigmatización de las minorías, o instrumentalización del miedo, entre otros.

En 2003 Marta Sanz publica Animales domésticos, novela de abierta inspiración galdosiana con la que consolida en su narrativa el punto de inflexión introducido con Los mejores tiempos (2001) al desplazar el 
centro de conciencia desde la pura individualidad hacia la intersección entre lo individual y lo colectivo (Simó, 2014, p. 43). La dialéctica entre el sujeto y su entorno, al igual que otros rasgos esenciales de la poética realista, como pueden ser determinadas estrategias narrativas o la trascendencia simbólica de la materia, establece un importante punto de continuidad entre el paradigma decimonónico y el que la autora practica a principios del siglo XXI. Esta comprensión de la colectividad como una red de relaciones que además de incardinar al individuo en un sistema, lo construye como sujeto, favorece la aparición de un recurso que es central en la obra de Galdós y en la de otros maestros realistas: la configuración de la familia como representación de toda la organización social. También en los textos de la autora, y con la intención de "dar cuenta de fragmentos representativos de la sociedad española contemporánea”, el espacio simbólico de la familia se configura, a partir de las dos novelas citadas, como el microcosmos en el que se traslucen "las contradicciones entre hombres y mujeres, jóvenes y viejos, ricos y pobres, una ideología reaccionaria y otra que no lo es" (Díaz, 2008). La institución familiar es también el corazón humano de otras obras posteriores, entre las que se incluyen Susana y los viejos (2006), obra en la que Adriana Bonatto identifica una clara voluntad, por parte de Sanz, de reescribir la tradición literaria del realismo galdosiano (2017, p. 10). La institución familiar es también el corazón humano de otras obras posteriores, entre las que se incluyen La lección de anatomía (2013), Daniela Astor y la caja negra (2014) o Amour fou ([2004] 2013), donde se da una versión subvertida de la misma. Tres personajes - Raymond, Elisa y la hija de ésta, Esther- conviven aquí como una familia sin serlo, unidos sólo por un plan urdido desde el deseo irracional de venganza contra Lala y Adrián, por lo que esta artificiosa alianza ofrece en realidad una lectura irónica y transgresora de los valores que tradicionalmente se atribuyen a los lazos de parentesco. Y esto es así, no únicamente por la tensión entre las apariencias y la realidad que tal impostura sugiere, sino porque se plantean en la novela cuestiones como el carácter interesado de algunas relaciones familiares, el egoísmo subyacente en el afán de perpetuar la especie o el tabú del rechazo de una madre hacia su descendencia, ya esbozado en Animales domésticos.

El modelo del microcosmos familiar aparece también modificado en Farándula (2015), donde los vínculos entre los personajes no vienen determinados por la consanguinidad, sino que se establecen de acuerdo con lazos puramente personales, ya sean de amistad, rivalidad o dependencia. El contexto que los enmarca esta vez es mucho más universal y podría expresarse mediante la figura retórica de "la gran familia del teatro". En ella los individuos siguen formando parte de una estrecha red de relaciones, por lo que sus motivaciones, deseos o frustraciones siguen nutriendo la densidad temática de la historia, sin embargo se pone en cuestión el modelo familiar sacralizado por la moral social. Aparecen aquí tipos femeninos para los que la reproducción no es un acto de afirmación ontológica o social - "Sí, soy un animal, pero no necesariamente un mamífero", le espeta Ana Urrutia a un periodista "muy preocupado por su esterilidad, su naturaleza de Yerma o acaso de Bernarda Alba" (2015, p. 35) - aunque prevalezca en el imaginario colectivo la tendencia a estigmatizar a aquellas mujeres que han renunciado a la maternidad:

\footnotetext{
La mujer sin familia hoy pagaba el precio de su indomabilidad y su carácter arisco. [...] Su decisión de no perpetuarse en hijos que ahora le habrían cogido la mano, velado por las noches, arropado con una mantita y cambiado el pañal. El yo, mí, me, conmigo de Ana Urrutia le estaba pasando factura en sus horas más tristes, pero Valeria Falcón sabía bien que esa renuncia a ser madre había constituido por parte de la Urrutia un acto de generosidad heroica. Nadie que ame a sus hijos puede querer que estén ahí para soportar delirios nocturnos, fecalomas, incontinencias urinarias, exabruptos e insultos que parecen salidos de las fauces de una niña a la que le urge un exorcismo: la rabia del que nota cómo va convirtiéndose en madera de sarmiento mientras llega la muerte que llama a la puerta, con los nudillos duros, haciendo toc, toc. $(2015$, p. 69).
}

Como la propia autora ha afirmado, todos sus libros surgen de libros anteriores (Rodríguez, 2015), por lo que además de esta reflexión en torno a la presión social que reciben las mujeres en relación con la maternidad, se deslizan también en este texto otros núcleos temáticos recurrentes en su obra, tales como la precariedad laboral, las falacias culturales que nos ofrecen los medios de comunicación, el desencanto o la superficialidad como forma de vida. 
En Black, black, black (2010), la primera de sus novelas con elementos del género negro, Marta Sanz actualiza otra forma de representación social propia del realismo decimonónico: la casa de vecindad. El microcosmos endogámico de la familia se traslada ahora a una comunidad de vecinos del centro de Madrid que, al más puro estilo realista, se erige también en configuración abstracta y simbólica de algunas de las líneas fundamentales del entramado social de hoy:

En ella hay seres y estratos muy reconocibles por todos nosotros, desde los inmigrantes, que tienen una presencia permanente en nuestra vida cotidiana, hasta los ancianos, que son una constante en mi obra porque son un sector que se ha hecho invisible o que se trata con una ternura blanda que me desagrada muchísimo. (Sainz Borgo, 2011, p. 60).

Tanto el inmenso inmueble parisino en que transcurre la acción de L’Assomoir (1876), de Zola, como la corrala de la calle Mira el Rio de Fortunata y Jacinta (1886-1887), por citar dos de los ejemplos más paradigmáticos de este espacio simbólico, son la representación de la clase trabajadora, una nueva realidad que estaba emergiendo en el siglo burgués por excelencia, y cuyas privaciones y falta de oportunidades para escapar a la miseria son descritas en toda su crudeza. Cuando la benefactora Guillermina Pacheco y Jacinta visitan el "cuarto estado", en el capítulo IX de la Parte Primera de Fortunata, se revela para la joven burguesa un mundo hasta entonces desconocido, el de la extrema pobreza, amenazante, conmovedora y repulsiva a partes iguales. Como Linda M. Willem ha observado, todo lo que allí vemos es revelado desde la perspectiva de Jacinta, criada entre los algodones de su clase media alta, por lo que esa "descripción filtrada", que si bien no contiene los pensamientos del personaje, como sucedería si se tratara de un monólogo interior o una narración en estilo indirecto libre, se construye a partir de sus impresiones, cargadas de recelo y negatividad (1998, p. 87). Son los miedos y prejuicios de su clase, así como la ignorancia respecto a otras realidades humanas, los que determinan la presentación del patio y los corredores de la casa de vecinos de Mira el Río, en los que se ofrece la estampa más degradada de la marginación social, palpable en la suciedad de las paredes, en la dureza del lenguaje, en el alboroto o en el desorden y el caos que preside la escena:

No tardaron en encontrarse dentro de un patio cuadrilongo. Jacinta miró hacia arriba y vio dos filas de corredores con antepechos de fábrica y pilastrones de madera pintada de ocre, mucha ropa tendida, mucho refajo amarillo, mucha zalea puesta a secar, y oyó un zumbido como de enjambre. En el patio, que era casi todo de tierra, empedrado sólo a trechos, había chiquillos de ambos sexos y de diferentes edades. [...] Los chicos eran de diversos tipos. Estaba el que va para la escuela con su cartera de estudio, y el pillete descalzo que no hace más que vagar. Por el vestido se diferenciaban poco, y menos aún por el lenguaje, que era duro y con inflexiones dejosas. [...] Avanzaron por el corredor, y a cada paso un estorbo. Bien era un brasero que se estaba encendiendo, con el tubo de hierro sobre las brasas para hacer tiro; bien el montón de zaleas o de ruedos, ya una banasta de ropa; ya un cántaro de agua. De todas las puertas abiertas y de las ventanillas salían voces o de disputa, o de algazara festiva. ([1887] 2015, p. 216-220).

La realidad del texto es una refracción de la conciencia que la percibe. También la casa de vecinos de Black, black, black lo es. Ésta se presenta en la historia mediante una descripción focalizada por Arturo Zarco, el detective esteta acostumbrado a tratar de mantener sus prejuicios a raya, aunque no siempre lo consiga. $\mathrm{Y}$, quizá a consecuencia de este ejercicio de ultracorrección, la imagen que Zarco nos transmite es la de un sistema armónico, ordenado, limpio, cuidado. Un lugar construido y dispuesto en aras del bienestar. Un mundo idealizado en el que la única nota discordante es el aspecto poco saludable del niño que juega en el patio:

El portal no es lujoso ni grande. Es estrechito y adornan el techo coquetas molduras pintadas de rojo. El suelo es de mármol blanco, entreverado de hilos de humo, con cenefas también rojas. En primer plano, una escalera con los peldaños de madera y la barandilla metálica rematada en una bola dorada; el pasamano también es de madera barnizada, brillante. Más allá se vislumbra un patio con una fuente y, al fondo, la escalera interior. En el patio un niño de unos cuatro o cinco años, vestido con un peto, pedalea en el edificio: su aspecto no es muy saludable, pero debe de ser una criatura fuerte porque sus pedaladas son enérgicas [...]. En los alféizares de las ventanas del patio interior los vecinos han puesto arbolitos enanos y tiestos con flores. Contra el cuadrado azul del cielo se dibujan las formas de la ropa tendida; destaca sobre todo la ropa interior de los hombres y de las mujeres, de los jóvenes y de los viejos: las bragas extragrandes, los calzoncillos de marca, los sostenes con relleno líquido, los simpáticos calcetines colgados por la punta, las camisetas de algodón, los tangas, los visos y las combinaciones... Huele a suavizante, a palitos de incienso y a un caldo de verduras que abre el apetito. Por una rendija se filtra hasta la oquedad 
del patio una relajante música de cuerda. El patio es un rectángulo secreto que nadie adivinaría desde el exterior. Un lugar agradable para vivir en el que posiblemente los vecinos se pidan tacitas de sal y se feliciten las pascuas. (2010, p. 23-24).

Estamos en un "barrio tan vulgar, como cualquier otro barrio del centro de la ciudad", nos dirá más tarde Paula, otro personaje que en esta novela actúa como focalizador (2010, p. 229). Se consolida así la idea de que esta casa de vecinos sigue siendo el espacio simbólico de las clases trabajadoras, o de ese umbral cada vez más ambiguo entre la clase trabajadora y la clase media baja de las sociedades del bienestar que, para la autora, "refleja en su vida cotidiana, en sus modos de relación, todas las perversidades del sistema en el que vivimos, todo lo que asumimos como normal" (Sainz Borgo, 2011, p. 60). Sin embargo, el impacto visual y sensorial de esta descripción es el reverso de la imagen que capta la mirada de Jacinta. Han cambiado las condiciones de vida, así como los términos para codificarla, pero del mismo modo que en el gran inmueble de la calle Mira el Río existe una jerarquía entre los pobres y los todavía más pobres, simbolizada por un segundo patio en el que las habitaciones se hacen aún más estrechas y miserables que en el primero, y entre los que dista "un escalón social" ([1887] 2015, p. 221), también en el microcosmos de Black, black, black se establece una clara división entre los residentes de las luminosas viviendas que dan a la calle y los resentidos habitantes de los pisos interiores, "encerrados en sus treinta metros, sin luz natural, alrededor de una mesa camilla con braserito” (2010, p. 117). Si algo no ha cambiado respecto a la realidad histórica del siglo XIX es el hecho de que el verdadero determinante social es el dinero.

Asimismo, el inframundo de la calle de Mira el Río se ha transformado aquí en un retrato menos monolítico que, ajeno a los miedos y recelos de la joven e ingenua burguesa que contempla la pobreza de frente por primera vez, presenta la alteridad y la diversidad desde la mirada intencionalmente neutra de un detective políticamente correcto. El mundo plural de esa casa, con sus diferencias sociales, raciales, económicas, de género y de edad, reflejado en la variedad de ropa interior tendida en la azotea del edificio, parece conformar un sistema avenido y solidario. Sin embargo, y en esto consiste el juego narrativo de la novela, progresivamente irán aflorando a la superficie, a través de la mirada de otros personajes, las perversiones escondidas, los gritos y los olores nauseabundos que se propagan por el patio, los malos tratos a los viejos y a los niños, los rencores y prejuicios atesorados a lo largo de los años, la desconfianza hacia la amabilidad del prójimo, el miedo al otro, el rechazo de lo que no se comprende, el interés disfrazado de altruismo, la pederastia. Todo un sustrato de sordidez en el que se concentra una de las intenciones críticas, no sólo de esta novela, sino de toda la obra de Marta Sanz: la doble voluntad de desvelar las verdades incómodas y de desmontar las "falacias de la doble moral" (Sainz Borgo, 2011, p. 60). O dicho de otro modo, la reflexión crítica de la autora no se centra únicamente en la esencia de la realidad, sino también en la elaboración retórica de la misma: en el uso de la parodia, de los términos despectivos o de los eufemismos, en lo que se puede o no se puede nombrar.

Es indudable que la obra de Marta Sanz se sitúa en las antípodas de lo que ella misma ha venido a llamar "ficción balsámica", metáfora con la que se refiere a aquellos productos culturales o pseudoculturales, como la prensa rosa, que infantilizan a los miembros de la sociedad protegiéndolos de todos aquellos aspectos que puedan hacerlos sufrir o que puedan provocar en ellos una reacción crítica. Es éste un fenómeno que coincide con la progresiva desaparición del lenguaje del compromiso, materializado en palabras como solidaridad, libertad, igualdad, conciencia critica o humanismo, entre otras (2014a, p. 45). Son precisamente todos estos términos robados al habla cotidiana los que conforman el armazón conceptual de la obra de Sanz, erigida como sostiene Cristina Somolinos- "con la vocación política de abrir grietas en los discursos hegemónicos de la sociedad española” (2016, p. 20).

Amour fou, escrita con la voluntad expresa de denunciar el cinismo moral de nuestra sociedad, y relegada durante años al limbo de lo no vendible, es un relato siniestro sobre la irracionalidad, la obsesión y la paranoia, "esa forma de censura que nos lleva a hablar bajito de ciertos temas dentro de los bares y a retirar la correspondencia del buzón rápidamente” ([2004] 2013b, p. 131). La condena colectiva a Lala por parte de la comunidad de vecinos y la automática presunción de culpabilidad de Adrián reproducen en el texto la 
inflexibilidad e intolerancia con que la sociedad y el sistema tienden a singularizar a aquellos cuyas opiniones resultan incómadaş.junio 2018, vol. 18, n²7, e021. ISSN 1852-4478

En No tan incendiario, nos recuerda Marta Sanz que existe una literatura con voluntad política, alejada de lo planfletario, que interroga el texto desde dentro e indaga sobre sus límites, pero que, lejos de ser simplemente un ejercicio de endoliteratura o pura experimentación formal, habla también del precio de las patatas, de la precariedad, la emigración o la condición femenina; habla de todos aquellos temas, en suma, "que han alimentado tradicionalmente la inquietud y la literatura política" (2014a, p. 139). Afín a este planteamiento, la autora asume en su escritura la responsabilidad de exponer y cuestionar todos aquellos aspectos que revelan las deficiencias y las injusticias del orden social contemporáneo y que, en última instancia, están minando también la dignidad humana de sus individuos. Es por ello habitual encontrar en sus tramas una serie de líneas recurrentes, así como determinados tipos humanos, trazados con una vena satírica incuestionable, que conforman los núcleos temáticos de su obra. Entre ellos, además de la ya mencionada cuestión de las apariencias de integridad minadas por la doble moral, destaca también una preocupación constante por la precariedad laboral y el empobrecimiento de las clases medias, de las cuales se hace un cuidadoso estudio en Animales domésticos (2003). La figura galdosiana del cesante se reescribe en esta novela, y en el contexto de la historia contemporánea, con la figura de Elías: el buen empleado que acaba en el sumidero del paro y que, incapaz de recuperar su lugar en una clase de la que ya ha quedado definitivamente descolgado, se condena a sí mismo al ostracismo de la indigencia. Su relato se entreteje, entre otros, con el de su hermano Esteban, el niño bien que juega a ser obrero, y el del compañero de éste, Jarauta, chico de taller de los barrios proletarios y melómano: "al fin y al cabo", piensa Esteban, "pertenecen a una nueva y especial clase media, entre el poder adquisitivo de la burguesía y las condiciones de trabajo del lumpen proletariado. Les queda ese hueco" (2003, p. 175). En Farándula, el fantasma de la precariedad laboral se aborda desde el ámbito de la cultura, una industria en la que sus trabajadores son los auténticos héroes contemporáneos de una batalla perdida de antemano: sin subvenciones, a merced de los recortes, de los inevitables parones laborales y de un públ No tan incendiario (2014a, p. 61). La degradación de la cultura a mero artefacto lúdico es también una consecuencia de la crisis, de la falta de pudor para mostrar la propia ignoraico cada vez más ignorante, pues "la sensibilidad colectiva no surge por generación espontánea", afirma la autora enncia, del triunfo de la economía neoliberal que legitima la cultura "en función de su rentabilidad y su presencia anestésica" (2014a, p. 21).

Todas estas son las cuestiones que determinan la textura de la literatura política para Marta Sanz, quien a la manera de los grandes maestros realistas, sólo puede hablar de los grandes conflictos de la colectividad a partir de la experiencia vital del individuo:

Como me parece que la economía y sus crisis marcan la pauta de nuestra sensibilidad, de nuestra manera de entender el amor, la amistad, el odio la piedad o cualquiera de los llamados grandes temas de la literatura, algunos relatos intimistas, algunas narraciones sentimentales - no sentimentaloides- o eróticas, me parece que tienen una dimensión política mucho más marcada que ciertos relatos políticos convencionales que buscan la fibra sensible y la gratificación de los lectores a partir de la repetición de propuestas retóricas reconocibles. (Eusebio, 2014, p. 118).

\section{LA FORMA ES IDEOLÓGICA}

La poética realista se fundamenta en la observación de la realidad. Autores como Zola, Galdós o Alas han hablado en sus textos teóricos de la importancia de este primer paso que, inevitablemente, conlleva un proceso de selección e interpretación. E interpretar la realidad, tanto la natural como la interior, significa posicionarse ideológicamente ante ella. En este sentido, la poética narrativa de Marta Sanz no puede estar más acorde con los postulados de los grandes maestros del XIX:

Creo que si los escritores tenemos un procedimiento de trabajo, o alguna función, es la de observar. Yo considero que los escritores son observadores de la realidad y a partir de ella dentro de las obligaciones morales que podamos asumir, ofrecemos 
un retrato del mundo en el que vivimos, y que me gustaría que fuese absolutamente distinto al que percibimos en los medios de comunicación, es decir, a la música ambiente. Yo me obligo a interpretar la realidad desde otro lugar y procurar intervenir en ella desvelando ciertas falacias de la doble moral. (Sainz Borgo, 2011, p. 60).

Desde la teoría de la literatura ya se ha destacado la capacidad generativa de los elementos paratextuales de una novela -entre los que se incluyen el título o los epígrafes que aparecen al principio de la misma-, pues abren un horizonte de expectativas para el lector y en ellos se empieza construir el significado de la obra. El título de la novela de 2008, La lección de anatomía, funciona como una metáfora de este axioma del realismo. Este título, que procede de un cuadro de Rembrandt, La lección de anatomía del doctor Nicolaes Tulp (1632), visualiza conceptualmente este primer momento de la creación: la observación positivista de la realidad. En el óleo de Rembrandt el doctor Tulp disecciona el brazo de un cadáver ante una reducida audiencia de siete hombres, en cuyos rostros podemos apreciar las distintas sensaciones provocadas por la visión de los tendones y los músculos: desde el profundo interés a la impasibilidad. La analogía que se establece entre esta imagen pictórica y el universo narrativo del texto es doble. Por un lado, del mismo modo que la autopsia permite conocer y entender los mecanismos internos del cuerpo, la disección que la protagonista de la novela lleva a cabo de su propia historia, a partir de recuerdos e impresiones, abre una vía hacia los resortes intangibles de su ser interior. Por otro lado, del mismo modo que el doctor Tulp se dirige a una audiencia, también la Marta Sanz ficcionalizada que traza una ambigua frontera entre la autobiografía y la novela, ofrece su interioridad a sus lectores, en un valiente acto de exhibicionismo emocional que es refrendado simbólicamente al final de la obra con la descripción de otra impactante imagen pictórica: el autorretrato de su propia desnudez.

Por supuesto, lo que caracteriza verdaderamente a un escritor realista no es únicamente su capacidad de observación, sino también la forma en que articula el discurso, maneja una determinada técnica o usa un determinado lenguaje, algo que los grandes teóricos y autores del realismo decimonónico resumieron en una palabra: experimentación. La elaboración de ese retrato del mundo que es el texto realista constituye, pues, un trabajo de imaginación artística que cristaliza en las descripciones, en las metáforas, en la selección de un punto de vista y un lenguaje, en la estructura del texto. Sin embargo, es fundamental anotar que todos estos aspectos del discurso del relato se organizan con el fin específico de ofrecer una determinada visión de la realidad -verosímil, parcial, política-, por lo que, como Marta Sanz ha afirmado, "las formas del arte, el estilo, son proyecciones ideológicas que a su vez alimentan la ideología” (Eusebio, 2014, p. 118).

Si retomamos, por un momento, la terminología decimonónica, podemos afirmar que también la poética realista de la autora descansa en la adecuación del binomio observación-experimentación, pues de ese primer momento del proceso creativo arrancan los temas que cimientan el compromiso ético de su obra. Sin embargo, aunque los parámetros estéticos del realismo del XIX siguen, en gran medida, presentes en su prosa, quizá es en esta dimensión verbal de texto donde se puede observar con mayor claridad la brecha de más de cien años que separa un momento del realismo del otro.

En su serie de cinco artículos "Del estilo en la novela", publicada en la revista Arte y Letras entre julio y diciembre de 1882, Leopoldo Alas arremetía contra la hinchazón y la aparatosidad que todavía imperaban en el lenguaje literario, y reclamaba para la novela formas de expresión que estuvieran acordes con las ideas que en ella se transmitían. Si por fin había llegado el momento de dejar atrás el idealismo y poder hablar de todo aquello que hasta entonces se había considerado indigno de la literatura, el lenguaje tenía que adaptarse a esta nueva circunstancia. Cuatro eran los adjetivos que Alas proponía para caracterizar el estilo más apropiado para la nueva forma de novela: natural, sencillo, expresivo y modesto. Una reflexión parecida se da en el caso de Marta Sanz, quien también se plantea una adecuación de la forma a los temas de la novela cuando afirma que "cada historia ha de buscar su propio lenguaje" (Eusebio, 2014, p. 118), hasta el punto de escribir "feo de lo feo", en el sentido de que el discurso no debe servir en ningún caso para embellecer una realidad miserable (2014a, p. 52). El escritor Rafael Chirbes, en su prólogo a la edición de La lección de anatomía de 2014, es quien mejor ha perfilado las líneas básicas del estilo de Marta Sanz. A tenor de sus palabras, la sencillez y la expresividad que Alas sugería como condiciones esenciales del lenguaje realista, siguen ahí: 
En apariencia, nada más alejado de la escena pintada por Rembrandt y del severo ambiente que la rodea que el teatro literario de idéntico título al que nos traslada el libro de Marta Sanz: su estilo ágil (salpicado de fogonazos brillantes), su inusual habilidad para recrear situaciones y para penetrar en la psicología de los personajes, y su fino oído para capturar la lengua hablada con una vivacidad admirable convierten la escritura de nuestra novelista en una gozosa representación de vida que en una melancólica o sombría manipulación de seres muertos. (2014b, p. 8).

En el discurso narrativo de Marta Sanz predominan las líneas nítidas, las frases breves, la inmediatez del presente narrativo. Es ésta una forma de naturalidad que la autora identifica con la "sobriedad bien educada del estilo adelgazado" y que define con sus propias palabras clave: "economía y sensación de que, con cuatro trazos, se refleja la profundidad del cosmos" (2014a, p. 54-55). Como en el caso de Alas, esta sencillez obedece a una reflexión sobre la forma y sobre cómo los modos de expresión de la literatura deben adaptarse a las demandas de una realidad cada vez más fragmentada y compleja. Del mismo modo que Clarín rechazaba el conservadurismo literario que seguía lastrando un género que ya había iniciado su renovación, Marta Sanz reacciona contra la creciente simplificación de los modelos culturales, ante el "vínculo familiar y complaciente" que el texto realista establece a menudo con el lector (González et al., 2014, p. 24). Y aunque la autora declara seguir confiando en "el realismo como marco ético y estético", señala también que los géneros no pueden entenderse como estructuras estáticas y que "están ahí para ser subvertidos, más que utilizados" (2014a, p. 90-93).

Se necesita un punto de artificio que neutralice la empatía engañosa en el imperio de los reality shows y de la espontaneidad -natural- de los zafios. Un punto de artificio para sacar a la luz los forzamientos de la vida cotidiana: dormimos sobre camas de pinchos; vivimos en contractura permanente; asumimos la normalidad del estrés. Tal vez la tuerca retórica y la crispación lingüística desvelen lo que en la realidad hemos dejado de sentir como artificioso y ha llegado a parecernos justo. (2014a, p. 57).

La intención crítica y la voluntad intervencionista de la ficción, ese afán de impactar en la conciencia de los lectores y devolver a la literatura su estatus de "herramienta crítica para pensar y actuar de otra manera" (2014a, p. 21), no se concretan únicamente en la selección de los temas, sacando a la luz espinosas realidades sociales, sino también en la forma de organizar el discurso. La forma también construye el sentido, y el lenguaje con que se transmiten las ideas ha de ser tan provocador como las ideas mismas, de ahí que Marta Sanz afirme que asumir riesgos formales es asumir riesgos conceptuales (2014a, p. 57). ¿En qué consiste, pues, este punto de artificio? ¿Y qué fracturas presenta respecto a la invisibilidad del estilo tan preconizada por el realismo más tradicional?

En sus líneas básicas, la narrativa de Marta Sanz es fiel a los principios de verosimilitud, naturalidad y autenticidad, entendida ésta como un compromiso moral con la verdad que se quiere representar. La autora rechaza de manera expresa "la omnisciencia encubridora", que crea una ilusión de neutralidad, y la única omnisciencia en la que confía es la del estilo indirecto libre, que con tanto acierto filtraba la subjetividad del personaje en el realismo más tradicional (Eusebio, 2014, p. 118). Precisamente, su primera novela, El frío, publicada por primera vez en 1995, constituye un estudio sobre los límites de la omnisciencia. La estructura de la obra, que prefigura ya un perspectivismo que se convertirá en uno de los rasgos más distintivos del estilo de Marta Sanz, alterna una serie de capítulos en primera persona y dirigidos a un narratario, con otros capítulos en los que la realidad es narrada desde la omnisciencia objetiva. Este modo de presentación, aunque alejado de la neutralidad que tan engañosa le parece a la autora, se revela como insuficiente, y son las secciones en primera persona las que, desde una intensa subjetividad, dan la auténtica medida emocional de la historia. Los capítulos narrados desde el yo, en los que el motivo del viaje es el vehículo simbólico para expresar el final de un amor obsesivo y frustrante, constituyen el primer ejercicio de narrativa testimonial en la trayectoria de Marta Sanz. O por lo menos, eso parece sugerir la Marta Sanz ficcionalizada de La lección de anatomía (2014, p. 237). El frío se configura, pues, como una auténtica declaración de principios narrativos, ya que ejemplifica claramente la idea de que la responsabilidad de la escritura no se plantea únicamente respecto al momento histórico que al autor le ha tocado vivir, sino también respecto a su propia historia, a su verdad 
interior y, en última instancia, respecto al texto. "No decir yo cuando se trata de uno mismo no es solamente perjudicial para la higiene personal del escritor; es también, por el hecho de no anunciar los vínculos que le unen a sus personajes, una manera de traicionarlos", anuncia la cita de Donner que abre La lección de anatomía (2014, p. 20). Esta conciencia ética, que también Natalia Vara ha destacado en su estudio sobre esta misma novela (2015), es determinante en la construcción del discurso. Por ello no debe sorprendernos que en El frío se prefiguren ya algunas de las técnicas que caracterizarán la trayectoria posterior de la autora, como ese perspectivismo narrativo, que sólo puede interpretarse como un recurso intensamente realista, pues es el reflejo de la percepción que la autora tiene de la realidad que quiere representar: "múltiple, cubista y multiperspectivista" (Sanz, 2014a, p. 88).

Tampoco la reafirmación del yo en el discurso contraviene la poética del realismo, pues la ficción ha dejado de ser la máscara tras la que se esconde el sujeto y se ha convertido en el instrumento que lo construye. El uso de la primera persona es, en otras palabras, una intensificación del subjetivismo que también formaba parte de la realización más tradicional del paradigma. El hecho de que el narrador no manifestara su presencia no implicaba en absoluto la supresión de la intencionalidad ética y crítica de la obra, que en última instancia procedía del autor.

Otros recursos habituales en la obra de Marta Sanz -el uso recurrente de la metáfora, la ironía de los diminutivos, la funcionalidad de las descripciones, reducidas a veces a la esencialidad de una enumeración de conceptos-consolidan la actitud inquisitiva de la autora respecto a la forma. Sin embargo, el cuestionamiento de algunos procedimientos asociados a la estética realista más tradicional no implica una ruptura drástica con el paradigma, sino que con la transgresión se revela también la intención esencial del estilo, al liberar el discurso de cualquier tipo de simulacro. De lo que no cabe duda es de que tanto en lo que respecta a la voluntad crítica como en lo que se refiere a la adecuación de la forma a la intencionalidad de la historia, la escritura de Marta Sanz contrae un compromiso con el texto y con la verdad que sólo se puede calificar como realista.

\section{Conclusión Y CODA}

“A mis casi cincuenta años, no me puedo permitir un relato nebuloso de la niñez. Ésta es una historia sobre el adulto que todos los niños llevamos dentro y también sobre la niña que se ha quedado dentro de mí”, dice Catalina H. Griñán en Daniela Astor y la caja negra. "No me puedo permitir una historia de palabras dichas a medias o de libros de familia que guardan secretos inconfesables" (2013, p. 173). Valgan estas líneas como ilustración final de algunos de los aspectos centrales de la práctica narrativa de Marta Sanz: la autenticidad, el compromiso con el momento histórico y con las propias circunstancias, el juego de perspectivas en el tiempo y, ante todo, la afirmación del yo narrativo como vehículo para construir el sujeto. Pero sirvan también para lanzar una última reflexión sobre la manera en que ética y estética, la dualidad conceptual sobre la que descansa la poética realista, se convierten en su obra en materia del relato y dan lugar a uno de los temas centrales de su trayectoria literaria -la cuestión realista por excelencia-: la relación entre la realidad y la representación de la misma.

La imagen de la escritura como un espejo en que el sujeto se encuentra a sí mismo está presente ya en Animales domésticos (2003, p. 163), materializada en el diario con el que Elías intenta encauzar el sentido de su existencia. También en Amour fou, el cuaderno de Raymond, en el que anota sus observaciones de rutina y sus recuerdos con Lala, y que se inserta en la historia como otra perspectiva del relato, es el plano en el que el personaje trata de verbalizar y racionalizar lo absurdo de su venganza. Sin embargo, para Lala este cuaderno no representa más que "la tienda de un anticuario: cosas viejas, cachivaches, fotos retocadas que no necesito volver a contemplar porque se han quedado impresas en la retícula de arrugas que me rodea los ojos" ([2004] 2013, p. 61). El diario de Luz, en Black, black, black, con el que se introduce uno de los tres puntos de vista que articulan el relato, es otro ejemplo de "escritura proyectiva", es decir, "poner fuera algo que pertenece al dentro", como aclara el ficcional doctor Bartoldi (2010, p. 153). Y no menos catártico es 
el ejercicio de escritura de Valeria en Farándula, aunque éste no pase de ser un intento fallido de redimir su frustración: "Escribir no me libera. Es el desnudo y el desnudo es la pose, el gesto que descubre quiénes somos o quiénes quisimos ser" (2015, p. 226). En el juego narrativo de Farándula la metáfora de la escritura sirve ante todo para dejar al descubierto el andamio y las intenciones del texto. Esto hace que la oposición ontológica tradicional entre ficción y realidad se haga borrosa, no sólo en el universo textual de la novela, sino también más allá de sus límites, pues en la voz narrativa de Valeria nos parece oír la de la propia autora: "Yo no escribo para que nadie se reconozca en su parte inteligente, sino en su más abyecta y entrañable vulgaridad" (2015, p. 226).

Esta forma de relación entre la realidad y sus representaciones es el nudo conceptual de Daniela Astor y la caja negra, la ramificación ficcional de La lección de anatomía (González et al., 2014, p. 24). En ambos casos se narra el proceso de consolidación de una identidad a través de la reescritura de la experiencia, ya sea en la voz de un ente de ficción como Catalina H. Griñán, o en las palabras de una Marta Sanz que, a caballo entre la literatura y la vida, especula con frecuencia sobre el difícil equilibrio entre lo real y sus apariencias: "hay que tener cuidado porque uno es finalmente lo que aparenta ser" (2014, p. 57). Del mismo modo, al recordar las historias que le contaba su amiga Clara I., esta Marta Sanz ficcionalizada de La lección de anatomía nos da la clave para entender su propia biografía novelada: "Me da igual que sus relatos sean verdad o mentira. Me fascinan sus historias que ella narra como si estuviera revelando las claves de un secreto" (2014, p. 190). En Clavícula (2017), donde la autora vuelve a transformarse en su propio personaje, el relato del dolor físico esboza una metáfora de la lucha y el desgaste que conlleva la existencia, tanto en su dimensión más abstracta como en la más material.

La frontera entre la realidad y sus representaciones se desvanece en La lección de anatomía y en Clavícula: la imagen recurrente de la escritura como un espejo adquiere aquí forma tangible para recordarnos que el compromiso ético de Marta Sanz no sólo se refiere a la realidad histórica, a la verdad que existe más allá del lenguaje, sino también al sentido y la necesidad de la ficción.

\section{BiBLIOGRAFìA}

Alas, L. (1882). Del estilo en la novela III. En Arte y Letras. Recuperado de http://www.cervantesvirtual.com/obra-v isor/del-estilo-en-la-novela-0/html/ffc47b8c-82b1-11df-acc7-002185ce6064_2.html

Bonatto, A. V. (2017). Representación de identidades femeninas a partir de tradiciones masculinistas en Susana y los viejos de Marta Sanz. La Colmena, 94, 9-23.

Díaz, E. (2008). Entrevista con la escritora española Marta Sanz: La literatura no es inofensiva. La Jiribilla. Revista de Cultura Cubana, 355. Recuperado de http://www.lajiribilla.co.cu/2008/n355_02/355_44.html

Eusebio, C. (2014). Entrevista a Marta Sanz. Cuadernos hispanoamericanos, 768, 114-124.

Ferré, J. F. (2011). Mimesis y simulacro. Benalmádena: Eda libros.

González, S., Larraz, F. y Somolinos, C. (2014). Intersecciones entre relatos: literatura y discurso dominante. Entrevista a Marta Sanz. Contrapunto. Publicación de Crítica e Información Literaria, 10, $24-27$.

Jiménez, D. (2013). El sueño de la crisis produce libros. Tiempo, 1759. Recuperado de http://www.tiempodehoy.com/ cultura/el-sueno-de-la-crisis-produce-libros

Lissorgues, Y. (2001). Hacia una estética de la novela realista. En P. Aubert (Ed.), La novela en España (siglos XIX y $X X)$. Madrid: Casa de Velázquez, 53-72.

Oleza, J. (1984). La novela del siglo XIX. Del parto a la crisis de una ideología, Barcelona: Laia.

Pérez Galdós, B. (1991). La sociedad presente como materia novelable [1897]. En L. Bonet (Ed.), Ensayos de crítica literaria (157-165). Barcelona: Península, 157-165.

Pérez Galdós, B. (2015). Fortunata y Jacinta. Dos historias de casadas [1887], Madrid: Paradimage Soluciones. 
Riaño, P. (noviembre, 2014). Despidos, precariedad, desahucios y tratar al lector como si fuera tonto es violencia. $E l$ confidencial. Recuperado de http://www.elconfidencial.com/cultura/2014-11-22/despidos-precariedad-desahu cios-y-tratar-al-lector-como-si-fuera-tonto-es-violencia_500252/

Rodríguez Marcos, J. (noviembre, 2015). La lucidez es una navaja que se te clava en el ojo. El País. Cultura. Recuperado de https://elpais.com/cultura/2015/12/11/babelia/1449836682_702238.html

Ros Ferrer, V. (2014). Contar la transición, o cómo hablar de la china en el zapato. Entrevista a Marta Sanz. Kamchatka, 4, 257-263.

Sainz Borgo, K. (2011). La poética de la normalidad da un paso más dentro de lo siniestro cotidiano. Quimera: Revista de literatura, 326, 58-61.

Sanz, M. (2003). Animales domésticos. Barcelona: Destino.

Sanz, M. (2006). Susana y los viejos. Barcelona: Destino.

Sanz, M. (2010). Black, black, black, Barcelona: Anagrama.

Sanz, M. (2012). El frío [1995]. Madrid: Caballo de Troya.

Sanz, M. (2013a). Daniela Astor y la caja negra. Barcelona: Anagrama.

Sanz, M. (2013b). Amour fou [2004]. Miami: La Pereza Ediciones.

Sanz, M. (2014a). No tan incendiario. Cáceres: Periférica.

Sanz, M. (2014b). La lección de anatomia [2008]. Barcelona: Anagrama.

Sanz, M. (2015). Farándula. Barcelona: Anagrama.

Sanz, M. (2017). Clavicula, Barcelona: Anagrama.

Simó, M. (2014). Ética y estética en la novela realista contemporánea: de Miau (1988) a Animales domésticos (2003). Pasavento. Revista de Estudios Hispánicos, 2, 33-56.

Somolinos Molina, C. (2016). Marta Sanz: Cuerpo, escritura, ideología. Insula, 834, 20-23.

Vara Ferrero, N. (2015). Lecciones del 'yo': autobiografía, ficción y sujeto ético en Marta Sanz. RECIAL: Revista del Centro de Investigaciones de la Facultad de Filosofia y Humanidades, Área letras, 7, s/p.

Becerra Mayor, D., Arias Careaga, R., Rodríguez Puértolas, J. y Sanz, M. (2013).Qué hacemos para construir un discurso disidente y transformador con aquello que hoy sirve para enmascarar la realidad y transmitir ideología: la literatura. Madrid: Akal.

Willem, L. M. (1998). Galdós's Segunda Manera. Rhetorical Strategies and Affective Response. Chapel Hill: North Carolina Studies in the Romance Languages and Literatures. 